\title{
Linking Maternal Warmth and Responsiveness to Children's Self-regulation
}

\author{
Antje von Suchodoletz, Gisela Trommsdorff and Tobias Heikamp, \\ University of Konstanz
}

\begin{abstract}
The present study demonstrated that a more differentiated view of positive parenting practices is necessary in the study of children's acquisition of self-regulation. Here, the unique contributions of maternal warmth and responsiveness to distress to children's self-regulation were tested in a sample of 102 German mothers and their kindergarten children (51 girls and 51 boys). Behavior regulation and internalization of rules of conduct were examined as specific components of children's self-regulation. As expected, maternal warmth was positively related to the child's behavior regulation. Responsiveness to distress was positively linked to the child's internalization of rules of conduct. No significant interactions between maternal parenting and either the child's gender or effortful control were found. The results are discussed with regard to the unique functions that different parenting practices have for children's self-regulation.
\end{abstract}

\section{Introduction}

Learning to effectively self-regulate one's own behavior in accordance with social standards is critical to children's development. In the literature, various parenting practices that promote this process have been identified (e.g., Chen, Lui, \& Li, 2000; Friedlmeier \& Trommsdorff, 1999; Jones et al., 2008). There is a growing body of empirical evidence that details the extent to which a specific parenting practice has a unique effect on a specific developmental outcome (see, e.g., Davidov \& Grusec, 2006; Jones et al., 2008; Mize \& Pettit, 1997). However, studies reporting functionally different effects involving positive parenting practices in non-American samples are scarce. Moreover, it has been pointed out that considerable differences exist between the US and European cultures, for instance, regarding parents' naïve theories of child development and socialization goals (Harkness, Super, \& van Tijen, 2000; Keller et al., 2006). Therefore, the purpose of the present study was to clarify the association of two aspects of positive parenting with two types of children's self-regulation in a German sample of kindergarten children. Positive parenting includes behaviors such as support,

Correspondence should be addressed to Antje von Suchodoletz, University of Freiburg, Research Group 'The Empirics of Education', Department of Economic and Behavioral Sciences, Starkenstr. 44, 79085 Freiburg, Germany. Email: antje.von.suchodoletz@psychologie.uni-freiburg.de 
nurturance, and warm and appropriate discipline that promote a positive parent-child relationship (e.g., Tildesley \& Andrews, 2008). Specifically, we investigated maternal warmth and responsiveness to distress in relation to children's behavior regulation in a delay task and children's internalization of rules of conduct. Moreover, the effects of children's gender and temperament on the relations between positive parenting and children's self-regulation were investigated as previous research has shown that children's characteristics moderate relations between parenting and developmental outcomes (e.g., Bates, Pettit, Dodge, \& Ridge, 1998; Eisenberg et al., 2001). So far, however, most of these studies have focused on the development of externalizing problem behavior.

\section{Self-regulation}

Self-regulation is a broad concept that focuses on an individual's motivation and ability to modify his or her emotion and behavior to achieve goals (Kopp, 1982; McClelland et al., 2007; Trommsdorff, 2009a). As a superordinate construct, self-regulation includes narrower constructs such as the regulation of behavior (e.g., Kopp \& Wyer, 1994) and the internalization of rules of conduct (e.g., Kochanska, DeVet, Goldman, Murray, \& Putnam, 1994). Behavior regulation is defined as the ability to express or control one's impulses, motor responses, and other behavior (Wong et al., 2006). Behavior regulation in children progressively shifts from external to internal processes (Kopp, 1982; McClelland, Ponitz, Messersmith, \& Tominey, 2010). During development, children become increasingly aware of social standards. They learn to take a more active role in the self-regulation process and to regulate their behavior more independently of parental monitoring and intervention (Kochanska \& Aksan, 2006). Internalization involves adopting rules and norms, so that acting according to social standards is motivated not only by external consequences but increasingly by internalized rules (Grusec \& Goodnow, 1994). The development of behavior regulation proceeds on an observable level of concrete behaviors, whereas internalization implies the acquisition of conscience.

\section{Socialization of Self-regulation}

Psychologists have identified children's self-regulation as an important socialization goal of parents (e.g., Grusec, Goodnow, \& Kuczynski, 2000; Maccoby \& Martin, 1983). Typically, such socialization efforts begin in early childhood, when children become increasingly aware of the expectations of their social environment through parental rule-setting. For almost 30 years, research on parenting with regard to child outcomes was dominated by Baumrind's (1971) classification of parenting styles. A parenting style refers to a constellation of attitudes toward a child that is fairly constant over time and in a variety of contexts (Collins, Maccoby, Steinberg, Hetherington, \& Bornstein, 2000; Darling \& Steinberg, 1993; Maccoby \& Martin, 1983). However, Darling and Steinberg (1993) argue that for an understanding of the processes through which parenting influences child outcomes, one needs to differentiate between parenting style (e.g., authoritative or authoritarian) and parenting practices (e.g., warmth, responsiveness, and control). Individual parenting practices that often have been grouped together for research purposes can serve different functions for children's developmental outcomes (Maccoby, 2000; Porter et al., 2005). Specific parenting practices are used by parents to help children achieve particular socialization goals (Darling 
\& Steinberg, 1993; Mize \& Pettit, 1997). They operate in circumscribed socialization domains such as self-regulation, directly affect child behaviors (e.g., the ability to resist temptations), and have an impact on parents' socialization efforts (Mize \& Pettit, 1997). According to the specific developmental outcome in question, different parenting practices need to be investigated (Darling \& Steinberg, 1993; Grusec \& Davidov, 2007). Stewart and Bond (2002) stated, 'Instead of describing parenting characteristics by using typologies, an alternative approach is to dismantle typologies into their component parts' (p. 381; cf. also Darling \& Steinberg, 1993). Nonetheless, many studies take a global approach to positive parenting, in which different positive parenting practices are grouped together (Goldberg, Grusec, \& Jenkins, 1999; Porter et al., 2005). In particular, two aspects of positive parenting, warmth and responsiveness to distress, have often been treated as one because their characteristics and their functions for child development seem to be very similar. Research, however, demonstrated a wide variability in warm and responsive parenting (e.g., Cahill, Deater-Deckard, Pike, \& Hughes, 2007). MacDonald (1992) suggested that warmth and responsiveness to distress are not generally associated (such as that the level of warmth influences the effects of responsiveness and vice versa). Mize and Pettit (1997) found support for functionally different effects of these different aspects of parenting: responsive parenting (i.e., warmth, synchrony), accounted for unique variance in teacher ratings of children's social skills and aggression. Recently, a study by Davidov and Grusec (2006) has provided further evidence that warmth and responsiveness to distress are two distinct features of positive parenting. These features require different skills and resources from parents. Moreover, they serve different functions in children's development. Parental warmth is characterized by high degrees of affection, spontaneous expressions of positive emotions in parent-child interactions, and frequent praise of the child, as expressed by behaviors such as kissing and hugging the child (Davidov \& Grusec, 2006; MacDonald, 1992). As distinguished from warmth, responsiveness to distress focuses on parental reactions when a child is upset. Positive parental responsiveness to distress involves supportive reactions: for example, comforting or helping the child when he or she is facing an upsetting situation (Davidov \& Grusec, 2006).

\section{Warmth and Children's Behavior Regulation}

By frequently engaging their children in interactions involving positive emotions, love, and praise of the child, parents facilitate children's ability and motivation for behavior regulation. For instance, a parent consistently expressing love and affection induces positive mood in the child. The child, in turn, is willing to control impulses and behaviors in order to continue the positive and satisfying parent-child interactions (Grusec \& Davidov, 2007). Thus, parental warmth might be particularly related to children's development of behavior regulation. Studies have consistently demonstrated positive links between parental warmth and children's behavior regulation as assessed by parents' reports (e.g., Colman, Hardy, Albert, Raffaelli, \& Crockett, 2006). In a recent study by Jennings et al. (2008), a positive relation between maternal warmth and behavior regulation in toddlers was observed. Other studies (e.g., Eisenberg et al., 2005; Jones et al., 2008; Russell \& Russell, 1996), have shown that parental warmth was related to low levels of externalizing problems in children and that high levels of behavior regulation were likewise associated with the absence of externalizing problems in childhood and adolescence (Wong et al., 2006). Thus, parental warmth is expected to be positively related to behavior regulation. 


\section{Responsiveness to Distress and Children's Internalization of Rules of Conduct}

The process of internalization is accompanied by children's experience of and coping with negative emotions, for instance, when being scolded for some mischief. Parents' active strategies affect how a child copes with these experiences. Responsive strategies help a child to acquire and to internalize social rules and standards (e.g., Kochanska \& Thompson, 1997), thus enhancing a child's motivation and ability to comply with parental demands and to internalize rules of conduct (Karreman, van Tuijl, van Aken, \& Deković, 2006; Kochanska \& Murray, 2000). According to Maccoby and Martin (1983), responsive parenting practices facilitate children's understanding of principles of cause and effect. These practices influence how open children are to parental socialization efforts and how willingly they learn to make appropriate choices (Grusec \& Goodnow, 1994). Parental responsiveness thus facilitates children's motivation to meet situational demands. Further evidence is provided by a study examining the role of early vs. ongoing maternal responsiveness in predicting cognitive and social development in full-term and preterm children (Landry, Smith, Swank, Assel, \& Vellet, 2001). The results of this study showed that children's internalization is fostered when parents demonstrate consistent patterns of responsiveness to their children's emotional needs throughout infancy and early childhood. Correspondingly, we expected that responsiveness to distress is positively related to internalization of rules of conduct.

\section{Child's Gender and Effortful Control}

Previous studies (e.g., Bates et al., 1998; Blair et al., 2008; Davidov \& Grusec, 2006; Eisenberg, Hofer, \& Vaughan, 2007; Kochanska et al., 1994), have shown that gender and effortful control are relevant in the development of children's self-regulation. Several studies revealed gender differences in children's and adolescents' selfregulation: overall, girls have, compared with boys, stronger self-regulation skills (Duckworth \& Seligman, 2006; Matthews, Ponitz, \& Morrison, 2009; Raffaelli, Crockett, \& Shen, 2005). However, these findings appear to be unique to North-American samples and may not apply to other cultures, especially when observational measures of self-regulation are used (McClelland et al., 2010). Some studies investigating gender as a moderating link between parenting and self-regulation revealed mixed and inconsistent findings (e.g., Colman et al., 2006; Davidov \& Grusec, 2006). Davidov \& Grusec (2006) found that the child's gender, for instance, moderated the relationship between maternal responsiveness to distress and emotion regulation. The associations were obtained only for boys but not for girls. In contrast, in a study by Colman et al. (2006), child gender did not moderate the effects of parenting on later self-regulation.

Generally, effortful control has been defined as the competence to inhibit a dominant response and/or to activate a subdominant response (Rothbart \& Bates, 2006). Children's individual differences in effortful control may lead to different reactions to parenting. As a result, a child is more or less susceptible to parent behaviors (Belsky, 2005). Additionally, child protective factors such as effortful control may buffer the consequence of negative parenting (Bates \& Pettit, 2007; Rothbart \& Bates, 2006). Consistent with this view, effortful control has previously been identified as a moderator of the relation between parenting and children's self-regulation (e.g., Lengua, 2008; Xu, Farver, \& Zhang, 2009). A high level of effortful control in children, for example, reduced the risk of externalizing problems in a family context of corporal punishment (Lengua, 2008). 


\section{Study Aim}

Although there is a growing body of evidence for incremental effects of different parenting dimensions in the prediction of different child outcomes (e.g., Davidov \& Grusec, 2006; Mize \& Pettit, 1997; Pettit, Laird, Dodge, Bates, \& Criss, 2001; Reitz, Deković, \& Meijer, 2006), the specific functions of different parenting practices for children's self-regulation need to be untangled in more detail, especially in nonAmerican samples. In the present study, we expected that maternal warmth and responsiveness to distress would uniquely contribute to various self-regulation skills in kindergarten children. Maternal warmth was hypothesized to be positively related to the child's behavior regulation. Furthermore, we expected that maternal responsiveness to distress would correlate positively with the child's internalization of rules of conduct. In addition, we expected that the children's gender and effortful control would interact with parenting behavior (i.e., maternal warmth and responsiveness to distress), in predicting self-regulation skills: stronger associations were expected for girls compared with boys and for children with higher levels of effortful control in comparison with children with lower effortful control. Mother's level of education served as a control variable as research has found links between family demographic variables (i.e., parental education), and the factors of interest in the current study (e.g., Connell \& Prinz, 2002; Evans \& Rosenbaum, 2008; Howse, Lange, Farran, \& Boyles, 2003).

\section{Method}

\section{Participants}

Participants consisted of 102 mother-child dyads ( 50 percent girls; 4 years and 5 months to 6 years and 5 months, $M=66$ months). The mothers reported no evidence of any general medical disorder; for six children, a delay in language development was reported. The families were recruited from public kindergartens. The recruitment procedure included an information letter about the study that was distributed through kindergartens in Konstanz, a town in the south of Germany. Approximately, 700 mothers received a letter. Mothers $(\mathrm{N}=149)$ who agreed to participate were contacted by phone; 117 mother-child dyads finally attended the study. Fifteen participants had missing data, yielding the final sample size of 102 dyads. Participants were primarily of middle-class socioeconomic status. All families came from a European cultural background. The majority of children lived in a two-parent household ( 80 percent). Twenty-six children (25 percent) were living in one-child families, 61 (60 percent) had one sibling, and 15 (15 percent) had two or more siblings. All mothers had at least 12 years of schooling. Using ICSED-97 (Organization for Economic Co-operation and Development, 1999), to indicate the mother's level of education, 69 mothers (68 percent) in the sample had completed the first stage of tertiary education (i.e., BA or MA). Sixty-two mothers (61 percent) were currently employed, half of these working full-time.

\section{Procedures}

The mothers and children visited the laboratory of the Developmental and Crosscultural Psychology research group at the University of Konstanz twice within one week. During the first session, a delay task (explained in greater detail below) was conducted by a trained female graduate student in psychology. In a separate room, the 
mothers individually completed questionnaires on parenting practices, children's internalization of rules of conduct, and temperament. During the second session, the mothers answered an additional questionnaire on parenting practices. At the end of each session, the mothers and children received small presents. All mothers signed an informed letter of consent before participating in the study.

\section{Measures}

Measures that had not been previously used for German samples were translated by two German speakers fluent in both German and English. Divergent translations were checked and corrected.

Maternal Warmth. The child-rearing practices report Q-sort (Block, 1965), modified by Roberts $(1989,1999)$, measures parents' attitudes, behaviors, and feelings about their children using 99 item-cards, each with statements such as 'I express affection by hugging, kissing and holding my child' and 'My child and I have warm, intimate times together'. Mothers were asked to evaluate their parenting behavior by sorting the cards into nine piles, each containing 11 cards, according to the degree to which the items were descriptive of their parenting behavior (ranging from 1, 'These cards are most undescriptive', to 9, 'These cards are most descriptive'). The child-rearing practices report Q-sort items that asked directly about maternal responsiveness to distress $(\mathrm{N}=9)$ were deleted prior to analyses in order to avoid interference between the two variables. A criterion sort of warmth was used on the basis of independent ratings from six experts (see Roberts, 1989). Correlations between mothers' individual ratings and this criterion sort were computed. The correlation coefficient can range from -1.00 (low warmth) to 1.00 (high warmth).

Maternal Responsiveness to Distress. The coping with children's negative emotion scale (Fabes, Poulin, Eisenberg, \& Madden-Derdich, 2002), is a self-report instrument consisting of six subscales that represent different parental responses to children's negative emotions. The questionnaire includes 12 hypothetical situations of common emotionally evocative events that young children often experience (e.g., a bicycle accident or being rejected by a friend). The mothers answered questions about each situation on a 7-point scale (from 1, 'very unlikely', to 7, 'very likely'), indicating the probability that they would respond to the situation in the explained manner. Each question represents a typical response pattern for one of the six subscales: emotionfocused reactions, problem-focused reactions, expressive encouragement, distress reactions, punitive reactions, and minimization reactions. Studies have shown that the coping with children's negative emotion scale is a valid and reliable instrument for assessing parental responsiveness to children's distress (Fabes et al., 2002; Gentzler, Contreras-Grau, Kerns, \& Weimer, 2005). In the present study, Cronbach's alpha ranging from .70 to .86 for the six subscales were found. These are consistent with the results of other studies (Coutu, Dubeau, Provost, Royer, \& Lavigueur, 2002; Davidov \& Grusec, 2006). Following Davidov and Grusec (2006), a total score for responsiveness to distress was derived by averaging the six subscales (reversing the distress reactions, punitive reactions, and minimization reactions subscales).

Assessment of Behavior Regulation. The behavior regulation of the children was observed using the snack delay task of the laboratory temperament assessment 
battery - preschool version (Goldsmith, Reilly, Lemery, Longley, \& Prescott, 1993). The procedure was videotaped. The children were offered candy under the constraint that they were to wait with their hands in their laps until a bell rang before eating the candy. The procedure was introduced with a practice trial. Six trials followed with different pause lengths, varying between 0 and 30 seconds ( 5 seconds, 10 seconds, no pause, 20 seconds, no pause, and 30 seconds). To judge whether the child violated the given rule before the experimenter rang the bell (i.e., by reaching for the candy), two previously trained raters coded the video for each trial (with $0=$ no and $1=$ yes). Overall possible scores ranged from 0 to 6 . For analyses, the variable was recoded, with 0 corresponding to low behavior regulation and 6 to a high level of behavior regulation. Inter-rater reliability, computed for 30 percent of the cases, was good $(\kappa=.87)$.

Assessment of Internalization of Rules of Conduct. The maternal reports of conscience development (Kochanska et al., 1994) was used as a parent-report instrument to measure each child's internalization of rules of conduct. The original instrument consists of 100 items. The response format is a 7-point scale ranging from 1 ('extremely untrue, not at all characteristic') to 7 ('extremely true, very characteristic'). The maternal reports of conscience development was used in an abridged version because the questionnaires for this study were administered as part of a larger set of questionnaires relevant to other research questions. The items $(\mathrm{N}=43)$ forming the factor 'active moral regulation' were given to the mothers as a questionnaire according to the original sequence of items. This factor consists of four scales: confession (e.g., 'My child will spontaneously admit fault or wrongdoing, either verbally or nonverbally'), reparation (e.g., 'My child seems relieved when given an opportunity to repair a damage s/he has caused'), concern about others' transgressions (e.g., 'My child gets upset when a guest breaks a household rule'), and internalized conduct (e.g., 'My child clearly hesitates before doing something forbidden, even when alone'). The observed Cronbach's alpha, ranging from .74 to .87, were comparable with those of an American sample reported by Kochanska et al. (1994). The scales were averaged to form a single active moral regulation score (Cronbach's alpha $=.76$ ).

Assessment of Effortful Control. The children's behavior questionnaire (Rothbart, Ahadi, Hershey, \& Fisher, 2001) was used to measure each child's level of effortful control. Mothers completed the children's behavior questionnaire-short form, consisting of 94 items. In this parent-report measure, the mother indicates whether a statement about her child is true on a 7-point scale (from 1, 'extremely untrue of your child', to 7, 'extremely true of your child'). The instrument includes 15 scales that can be aggregated to three temperamental dimensions: effortful control, negative affectivity, and surgency. For our study, we adopted the factor solution of Rothbart et al. (2001) to derive the factor for effortful control. As in Kochanska et al. (1994), all items were checked for any face resemblance to items relevant to internalization of rules in order to avoid interference between these variables. Three items were consequently deleted. The scales 'inhibitory control' ('My child approaches sites, it has been told, that they are dangerous, slowly and carefully'), 'attentional focusing' ('When drawing or coloring in a book, my child shows strong concentration'.), 'low-intensity pleasure' ('My child enjoys gentle rhythmic activities, such as rocking or swaying'.), and 'perceptual sensitivity' ('My child seems to listen to even quiet sounds'), were averaged. The resulting Cronbach's alpha (.60) was lower than the Cronbach's alpha (.74) reported by Putnam and Rothbart (2006) for the very short form. The deletion of items did not alter reliability. 
Table 1. Descriptive Statistics $(\mathrm{N}=102)$

\begin{tabular}{|c|c|c|c|c|}
\hline & Measure & $M$ & $S D$ & Range \\
\hline \multirow[t]{2}{*}{$\begin{array}{l}\text { Mother's positive } \\
\text { parenting variables }\end{array}$} & $\begin{array}{l}\text { Responsiveness to distress } \\
\text { (CCNES) }\end{array}$ & 5.52 & .46 & $4.28-6.51$ \\
\hline & Warmth (CRPR) ${ }^{\mathrm{a}}$ & .64 & .18 & $.22-.84$ \\
\hline \multirow[t]{3}{*}{ Child variables } & $\begin{array}{l}\text { Internalization of rules of } \\
\text { conduct (MRCD) }\end{array}$ & 4.67 & .71 & $2.24-6.53$ \\
\hline & $\begin{array}{l}\text { Behavior regulation (Snack } \\
\text { Delay) }\end{array}$ & 2.56 & 1.93 & $0-6$ \\
\hline & Effortful control (CBQ) & 5.65 & .60 & $4.07-6.83$ \\
\hline
\end{tabular}

${ }^{a}$ Fisher's $z$-scores.

CCNES = coping with children's negative emotion scale; CRPR = child-rearing practices report Q-sort; MRCD = maternal reports of conscience development; $\mathrm{CBQ}=$ children's behavior questionnaire.

\section{Results}

\section{Preliminary Analyses}

The obtained correlation coefficients for maternal warmth were transformed using Fisher's $r$ to $z$ procedure to enable their use in data analysis (a common procedure when using Q-sort measures; e.g., Cassibba, Van IJzendoorn, \& D’Odorico, 2000; Roberts, 1999). This was done to adjust the distribution by converting Pearson's $r$ to the normally distributed variable $z$. Maternal warmth was relatively high in the sample. The scores for maternal responsiveness to distress were comparable with the means reported by Davidov and Grusec (2006): mothers perceived themselves to be highly responsive when confronted with their children's distress. Mothers also reported high scores for their children's internalization of rules of conduct and effortful control. The means were comparable with those reported in other studies (e.g., Kochanska et al., 1994; Komsi et al., 2006). The children's observed behavior regulation ranged from low (' 0 ') to high (' 6 '). Table 1 shows means and standard deviations of all variables.

$T$-tests of two independent groups revealed a significant effect of the child's gender only on his or her internalization of rules of conduct, $t(100)=-2.12, p<.05, \eta^{2}=.04$. Mothers reported a higher level of internalization of rules of conduct for girls $(M=4.82, S D=0.56)$ than for boys $(M=4.52, S D=0.82)$. Pearson correlations yielded no significant relations between the age of the child, the level of effortful control, and any predictor or outcome variable, respectively. However, the mother's level of education was significantly and positively related to her warmth. Therefore, the mother's level of education was entered in further hypotheses testing. The correlations are presented in Table 2 .

\section{Overview of Analyses}

The hypotheses were tested with hierarchical regression analyses. Behavior regulation and the internalization of rules of conduct served as dependent (outcome) variables. The first block included the mother's level of education and the child's gender (or 
Table 2. Inter-correlations Between Mother's Positive Parenting Practices, Mother's Level of Education, Child-age, Self-regulation, and Effortful Control

\begin{tabular}{|c|c|c|c|c|c|c|c|}
\hline $\mathrm{N}=102$ & 1 & 2 & 3 & 4 & 5 & 6 & 7 \\
\hline $\begin{array}{l}\text { Maternal responsiveness to } \\
\text { distress }\end{array}$ & - & & & & & & \\
\hline Maternal warmth & $.26^{* *}$ & - & & & & & \\
\hline Mother's level of education & -.04 & $.32 * *$ & - & & & & \\
\hline Child's age & .03 & -.09 & -.07 & - & & & \\
\hline $\begin{array}{l}\text { Child's internalization of rules } \\
\text { of conduct }\end{array}$ & $.21^{*}$ & .11 & -.01 & .04 & - & & \\
\hline Child's behavior regulation & .15 & $.29 * *$ & .13 & .03 & $.20 *$ & - & \\
\hline Child's effortful control & .06 & .04 & .06 & -.05 & .06 & .10 & - \\
\hline
\end{tabular}

$* p<.05, * * p<.01$.

effortful control). The second block included maternal parenting variables. Because maternal warmth and responsiveness to distress were positively and significantly correlated (see also Davidov \& Grusec, 2006), we entered both variables together in the second block to test the unique effects of maternal warmth and responsiveness to distress on the child outcome variables. Furthermore, we also tested whether maternal warmth and responsiveness to distress interacted with the child's gender or effortful control to predict any of the child's outcome variables, respectively. The interaction terms were entered in a separate third block. The variables were centered before the interaction terms were computed (Cohen, Cohen, West, \& Aiken, 2003).

\section{Predicting Children's Behavior Regulation}

First, we examined relations between parenting and children's behavior regulation. Consistent with our hypothesis, maternal warmth was a significant predictor of higher levels of behavior regulation, independent of any contribution of maternal responsiveness to distress. Neither of the child variables (gender and effortful control) nor the mother's level of education reached significance in predicting the child's behavior regulation. There were no significant interactions between the child's gender (effortful control) and the parenting variables, although the interaction between the child's effortful control and maternal responsiveness to distress approached significance $(p=.06)$. The results are presented in Tables 3 and 4 .

\section{Predicting Children's Internalization of Rules of Conduct}

The prediction of children's internalization of rules of conduct was considered next. Analyses yielded significant main effects for the child's gender and the mother's responsiveness to distress. Girls showed a higher level of internalization than boys. Consistent with our hypothesis, maternal responsiveness and children's internalization of rules of conduct were significantly and positively associated, whereas maternal warmth was not a significant predictor. Again, there was no significant effect of 
Table 3. Regression Analysis Predicting the Child's Behavior Regulation With Gender as Moderator

\begin{tabular}{llccc}
\hline & \multicolumn{4}{c}{$\begin{array}{c}\text { Dependent variable: } \\
\text { child's behavior regulation }\end{array}$} \\
\cline { 2 - 5 } & & $\mathrm{B}$ & $\mathrm{SE}(\mathrm{B})$ & $\beta$ \\
\hline Step 1: covariates & $R^{2}=.04$ & & & \\
Mother's level of education & & .35 & .25 & .14 \\
Gender & & .61 & .38 & .16 \\
Step 2: predictors & $\Delta R^{2}=.07^{*}$ & & & .11 \\
Responsiveness to distress & & .46 & .43 & $.22^{*}$ \\
Warmth & $\Delta R^{2}=.01$ & 2.43 & 1.18 & \\
Step 3: gender interaction & & .61 & .85 & .10 \\
Gender ${ }^{\mathrm{a}} \times$ responsiveness to distress & & 1.74 & 2.24 & .11 \\
Gender ${ }^{\mathrm{a}} \times$ warmth & & & & \\
\hline
\end{tabular}

Note: The full regression equation was significant: $F(6,94)=2.24, p<.05$. The full model explained 6.9 percent of the variance (adjusted $R^{2}=.069$ ).

${ }^{\text {a }}$ Dummy coded (boys $=0$; girls $=1$ ).

$* p<.05$.

Table 4. Regression Analysis Predicting the Child's Behavior Regulation With Effortful Control as Moderator

Dependent variable:

child's behavior regulation

\begin{tabular}{lrrc}
\hline & $\mathrm{B}$ & $\mathrm{SE}(\mathrm{B})$ & $\beta$ \\
\multicolumn{1}{c}{$R^{2}=.03$} & & & \\
& .32 & .25 & .13 \\
$\Delta R^{2}=.07^{*}$ & .31 & .33 & .09 \\
& .35 & .42 & .08 \\
$\Delta R^{2}=.04$ & 2.71 & 1.17 & $.25^{*}$ \\
& 1.58 & .81 & $2.17^{* *}$ \\
& .14 & 2.02 & .07
\end{tabular}

Note: The full regression equation was significant: $F(6,94)=2.45, p<.05$. The full model explained 8 percent of the variance (adjusted $R^{2}=.080$ ).

$* p<.05, * * p<.10$. 
Table 5. Regression Analysis Predicting the Child's Internalization of Rules of Conduct With Gender as Moderator

\begin{tabular}{|c|c|c|c|c|}
\hline & \multicolumn{4}{|c|}{$\begin{array}{l}\text { Dependent variable: child's } \\
\text { internalization of rules of conduct }\end{array}$} \\
\hline & & $\mathrm{B}$ & $\mathrm{SE}(\mathrm{B})$ & $\beta$ \\
\hline Step 1: covariates & $R^{2}=.04$ & & & \\
\hline Mother's level of education & & .00 & .09 & .00 \\
\hline Gender ${ }^{\mathrm{a}}$ & & .30 & .14 & $.21^{*}$ \\
\hline Step 2: predictors & $\Delta R^{2}=.06^{*}$ & & & \\
\hline Responsiveness to distress & & .38 & .16 & $.25^{*}$ \\
\hline Warmth & & -.14 & .47 & -.03 \\
\hline Step 3: gender interaction & $\Delta R^{2}=.05^{* *}$ & & & \\
\hline Gender $^{\mathrm{a}} \times$ responsiveness to distress & & -.29 & .31 & -.13 \\
\hline Gender $^{\mathrm{a}} \times$ warmth & & -1.44 & .82 & $-.24 * *$ \\
\hline
\end{tabular}

Note: The full regression equation was significant: $F(6,94)=2.70, p<.05$. The full model explained 9.3 percent of the variance (adjusted $R^{2}=.093$ ).

${ }^{a}$ Dummy coded (boys $=0$; girls $=1$ ).

$* p<.05, * * p<.10$.

the mother's level of education. There was no significant interaction between the child's gender and responsiveness to distress; however, the gender-maternal warmth interaction was marginally significant $(p=.08)$. A summary of results is presented in Table 5.

Table 6 shows the results of the regression analysis involving the child's effortful control as predictor. The mother's responsiveness to distress was again predictive of the child's level of internalization. The analysis yielded no main effects for the mother's level of education, maternal warmth, and the child's effortful control. Again, no significant interaction between the child's effortful control and responsiveness to distress was found. For maternal warmth, there was a significant interaction with the child's effortful control. Please note, however, that contrary to the previously presented results, the full regression equation of this analysis did not reach significance.

In summary, consistent with our hypothesis, maternal warmth significantly predicted behavior regulation, over and above the influence of maternal responsiveness to distress. In contrast, the child's gender and effortful control were not significant predictors or moderators in the prediction of behavior regulation. As expected, maternal responsiveness to distress significantly and positively predicted the child's internalization of rules of conduct when controlling for maternal warmth. The child's gender was also a significant predictor: girls showed higher levels of internalization than boys as reported by mothers. There were no significant interaction effects in the prediction of internalization. The mother's level of education did not reach significance, neither in the prediction of the child's behavior regulation nor in the prediction of internalization. 
Table 6. Regression Analysis Predicting the Child's Internalization of Rules of Conduct With Effortful Control as Moderator

\begin{tabular}{llrrr}
\hline & \multicolumn{4}{c}{$\begin{array}{c}\text { Dependent variable: child's } \\
\text { internalization of rules of conduct }\end{array}$} \\
\cline { 2 - 6 } & & B & SE(B) & $\beta$ \\
\hline Step 1: covariates & $R^{2}=.00$ & & & \\
Mother's level of education & & -.01 & .09 & -.01 \\
Effortful control & $\Delta R^{2}=.04$ & .07 & .12 & .06 \\
Step 2: predictors & & .32 & .16 & $.21^{*}$ \\
Responsiveness to distress & $\Delta R^{2}=.06^{* *}$ & .04 & .44 & .01 \\
Warmth & & .28 & .31 & 1.05 \\
Step 3: effortful control interaction & & 1.59 & .76 & $2.23^{*}$ \\
Effortful control $\times$ responsiveness to distress & & & & \\
Effortful control $\times$ warmth & & & & \\
\hline
\end{tabular}

Note: The full regression equation did not reach significance: $F(6,94)=1.83, p=.10$.

$* p<.05, * * p<.10$.

\section{Discussion}

The purpose of the present study was to specify the function of distinct positive parenting practices - maternal warmth and responsiveness to distress-in children's self-regulation (behavior regulation and internalization of rules of conduct) and to extend previous findings (e.g., Davidov \& Grusec, 2006) to a different population (i.e., a non-American sample). The results were consistent with our expectations and confirmed the necessity of a separate examination of maternal warmth and responsiveness to distress in regard to child outcomes (Davidov \& Grusec, 2006). In line with previous findings (e.g., Colman et al., 2006; Jennings et al., 2008; Karreman et al., 2006), maternal warmth was positively related to children's behavior regulation, whereas responsiveness to distress was positively associated with children's internalization of rules of conduct. Both parenting practices exerted their specific effects on child outcomes independently.

The present study extends previous work (e.g., Darling \& Steinberg, 1993; Davidov $\&$ Grusec, 2006; Mize \& Pettit, 1997), on functionally different effects of different parenting dimensions. Davidov and Grusec (2006) found evidence in favor of positive links between maternal warmth, children's emotion regulation, and peer group acceptance. Our study demonstrated that maternal warmth is also important for children's behavior regulation. In early childhood, behavior regulation begins to develop within the child-caregiver interaction (McClelland et al., 2010). Warm and supportive parenting, including positive emotional expressions (e.g., hugging), provides the emotional climate for the development of behavior regulation. Maternal warmth fosters a child's willingness to control his or her impulses and behaviors according to given rules in order to continue the positive parent-child interactions (Jennings et al., 2008). Part of 
the explanation is that maternal warmth promotes a child's enjoyment of interactions with the mother (Kochanska, Aksan, Prisco, \& Adams, 2008).

Furthermore, the results illustrate that the mother's responsiveness to distress specifically enhances children's motivation and ability to internalize rules of conduct. Internalization implies refraining from prohibited actions even when not under surveillance (Grusec \& Goodnow, 1994; Kochanska et al., 1994). A child caught in misbehavior may experience negative emotions, for example when she or he is scolded by the parent. The parent's responsive reactions to the expression of negative emotions, even though the parent is currently upset about the child's misbehavior, facilitate the child's emotion regulation (Bugental, 2000; Roberts \& Strayer, 1987). These links, however, may also be of more indirect nature. Because maternal responsiveness to distress is positively associated with a child's emotion regulation (Davidov \& Grusec, 2006), a child of a responsive mother is more motivated and better able to regulate his or her emotion during discipline situations and, thus, is more attentive to parental messages (Grusec \& Davidov, 2007).

Contrary to our expectations, we found no significant interaction effects of parenting variables and the child's gender or effortful control in the prediction of behavior regulation or in the prediction of internalization of rules of conduct. In contrast, other studies reported clear gender differences. For example, Russell and Russell (1996) reported a significant relation between warmth and rates of misbehavior in girls but not in boys, whereas Davidov and Grusec (2006) reported a significant positive association between maternal warmth and child peer acceptance in boys only. This pattern of results suggests that the mother's parenting practices impact boys' and girls' development differently (Colman et al., 2006). However, recently it has been suggested that gender differences may be unique to North American samples and to parent- or teacher-rated measures. No significant gender differences were found, for example, in Taiwanese, South Korean, and Chinese samples when using a direct measure of behavior regulation (McClelland et al., 2010). This possibility is consistent with our findings as we found gender differences only regarding parents' reports (mothers reported higher levels of internalization for girls than for boys) but not in the direct measure of behavior regulation. However, the lack of significant moderating effects in our study may as well be a consequence of the difficulty finding moderator effects in field studies (McClelland \& Judd, 1993).

Although the mother's level of education was statistically controlled in our study, the characteristics of the sample (e.g., socioeconomic background), and hence the kind of observed and reported behavior, need to be taken into account when interpreting the present findings. Mothers in the sample tended to show higher levels of warmth than in other studies due to sample characteristics. Maybe the importance of warm parenting arises primarily in samples with higher economic backgrounds. These mothers may be more sensitive to their children's abilities and capable of adapting their parenting to their children's developmental skills than mothers with less economic resources (Bakermans-Kranenburg, van IJzendoorn, \& Kroonenberg, 2004).

Similarly, the moderate correlation between maternal warmth and responsiveness to distress may be explained by measurement constraints. Both maternal warmth and responsiveness to distress were assessed through mothers' self-reports. However, the use of parental reports in the assessment of these constructs and the finding of a positive relation between warmth and responsiveness to distress is consistent with prior research (e.g., Davidov \& Grusec, 2006). Therefore, the level of warmth might influence the effects of responsiveness and vice versa. An alternative explanation of the 
shared variance between warmth and responsiveness is suggested by MacDonald (1992), who claims that warmth and responsiveness to distress are linked in western cultures but not universally. This explanation points to the necessity to integrate the role of culture into the study of parenting and development (Trommsdorff, 2006, $2009 \mathrm{~b}$ ). These limitations aside, the results still demonstrate that warmth and responsiveness to distress make unique contributions to different developmental domains. These results highlight the importance of disentangling parenting typologies or styles into their distinct components (Mize \& Pettit, 1997; Stewart \& Bond, 2002). Warmth and responsiveness operate in different socialization domains and serve different functions for child development (Davidov \& Grusec, 2006; Grusec \& Davidov, 2007; Roberts \& Strayer, 1987).

Several limitations of the present study however, should be noted. The study included cross-sectional data only. Although we are aware of the discussion of bidirectionality in the socialization of children (Collins et al., 2000; Grusec, 2006; Karreman et al., 2006; Trommsdorff \& Kornadt, 2003), no interpretation about the direction of effects or about long-term effects in the relationships between various aspects of positive parenting and self-regulation can be drawn from the present study. However, this criticism also applies to many studies where results have been interpreted to suggest that parenting influences self-regulation (Davidov \& Grusec, 2006; Dennis, 2006; Eiden, Edwards, \& Leonard, 2006). Further studies should include longitudinal data to determine the direction of the relations between positive parenting practices and child self-regulation. Additionally, our sample was not socioeconomically diverse, and it is possible that sample characteristics (e.g., mother's socioeconomic and educational background), may function as possible moderators of the connection between parenting and self-regulation (Paulussen-Hoogeboom, Stams, Hermanns, \& Peetsma, 2007). For a better understanding of potential moderator effects, more variation in sample characteristics is needed.

In conclusion, the pattern of results we obtained is consistent with the hypothesis that maternal warmth and responsiveness to distress are distinct positive parenting practices. Each makes unique contributions in the development of different aspects of self-regulation in kindergarten children. We therefore second the proposal of Davidov and Grusec (2006) that, contrary to the common practice of grouping warmth and responsiveness to distress together, these features of positive parenting are not interchangeable. However, further research is needed to untangle the different pathways through which various parenting practices uniquely contribute to children's different developmental outcomes. Other closely related parenting practices, like control, should be further studied as well to avoid oversimplification of complex interactions. This type of research has definite concrete applications: for early family intervention programs, for promoting parents' understanding of the specificity of the relationship between various parenting practices and their psychological meaning for different developmental outcomes.

\section{References}

Bakermans-Kranenburg, M. J., van IJzendoorn, M., \& Kroonenberg, P. M. (2004). Differences in attachment security between African-American and white children: Ethnicity or socioeconomic status? Infant Behavior and Development, 27, 417-433.

Bates, J. E., \& Pettit, G. S. (2007). Temperament, parenting, and socialization. In J. Grusec, \& P. Hastings (Eds.), Handbook of socialization (pp. 153-177). New York: Guilford. 
Bates, J. E., Pettit, G. S., Dodge, K. A., \& Ridge, B. (1998). Interaction of temperamental resistance to control and restrictive parenting in the development of externalizing behavior. Developmental Psychology, 34, 982-995.

Baumrind, D. (1971). Current patterns of parental authority. Developmental Psychology, 4, $1-103$.

Belsky, J. (2005). Differential susceptibility to rearing influence: An evolutionary hypothesis and some evidence. In B. Ellis, \& D. Bjorklund (Eds.), Origins of the social mind: Evolutionary psychology and child development (pp. 139-163). New York: Guilford.

Blair, C., Granger, D. A., Kivlighan, K. T., Mills-Koonce, R., Willoughby, M., Greenberg, M. T., et al. (2008). Maternal and child contributions to cortisol response to emotional arousal in young children from low-income, rural communities. Developmental Psychology, 44, 10951109.

Block, J. (1965). The child-rearing practices report (CRPR): A set of $Q$-items for the description of parental socialization attitudes and values. Unpublished manuscript. California: Institute of Human Development, University of Berkeley.

Bugental, D. B. (2000). Acquisition of the algorithms of social life: A domain-based approach. Psychological Bulletin, 126, 187-219.

Cahill, K. R., Deater-Deckard, K., Pike, A., \& Hughes, C. (2007). Theory of mind, self-worth and the mother-child relationship. Social Development, 16, 45-56.

Cassibba, R., Van IJzendoorn, M. H., \& D'Odorico, L. (2000). Attachment and play in childcare centers: Reliability and validity of the attachment Q-sort for mothers and professional caregivers in Italy. International Journal of Behavioral Development, 24, 241-255.

Chen, X., Lui, M., \& Li, D. (2000). Parental warmth, control, and indulgence and their relations to adjustment in Chinese children: A longitudinal study. Journal of Family Psychology, 14, 401-419.

Cohen, J., Cohen, P., West, S. G., \& Aiken, L. S. (2003). Applied multiple regression/correlation analyses for the behavioral sciences, 3rd ed. Mahwah, NJ: Erlbaum.

Collins, A. W., Maccoby, E. E., Steinberg, L., Hetherington, E. M., \& Bornstein, M. H. (2000). Contemporary research on parenting: The case of nature and nurture. American Psychologist, $55,218-232$.

Colman, R. A., Hardy, S. A., Albert, M., Raffaelli, M., \& Crockett, L. J. (2006). Early predictors of self-regulation in middle childhood. Infant and Child Development, 15, 421437.

Connell, C. M., \& Prinz, R. J. (2002). The impact of childcare and parent-child interactions on school readiness and social skills development for low-income African American children. Journal of School Psychology, 40, 177-193.

Coutu, S., Dubeau, D., Provost, M. A., Royer, N., \& Lavigueur, S. (2002). Validation de la version francaise du questionnaire coping with children's negative emotions scale - CCNES [Validation of the French version of the coping with children's negative emotions scaleCCNES]. Revue Canadienne des Science du comportement, 34, 230-234.

Darling, N., \& Steinberg, L. (1993). Parenting style as context: An integrative model. Psychological Bulletin, 113, 487-496.

Davidov, M., \& Grusec, J. E. (2006). Untangling the links of parental responsiveness to distress and warmth to child outcomes. Child Development, 77, 44-58.

Dennis, T. (2006). Emotional self-regulation in preschoolers: The interplay of child approach activity, parenting, and control capacities. Developmental Psychology, 42, 84-97.

Duckworth, A. L., \& Seligman, M. E. P. (2006). Self-discipline gives girls the edge: Gender in self-discipline, grades, and achievement test scores. Journal of Educational Psychology, 98, 198-208.

Eiden, R. D., Edwards, E. P., \& Leonard, K. E. (2006). Children's internalization of rules of conduct: Role of parenting in alcoholic families. Psychology of Addictive Behaviors, 20, $305-315$.

Eisenberg, N., Hofer, C., \& Vaughan, J. (2007). Effortful control and its socioemotional consequences. In J. J. Gross (Ed.), Handbook of emotion regulation (pp. 287-306). New York: Guilford.

Eisenberg, N., Losoya, S., Fabes, R. A., Guthrie, I. K., Reiser, M., Murphy, B. C., et al. (2001). Parental socialization of children's dysregulated expression of emotion and externalizing problem. Journal of Family Psychology, 15, 183-205. 
Eisenberg, N., Zhou, Q., Spinrad, T. L., Valiente, C., Fabes, R. A., \& Liew, J. (2005). Relations among positive parenting, children's effortful control, and externalizing problems: A threewave longitudinal study. Child Development, 76, 1055-1071.

Evans, G. W., \& Rosenbaum, J. (2008). Self-regulation and the income-achievement gap. Early Childhood Research Quarterly, 23, 504-514.

Fabes, R. A., Poulin, R. E., Eisenberg, N., \& Madden-Derdich, D. A. (2002). The coping with children's negative emotions scale (CCNES): Psychometric properties and relations with children's emotional competence. Marriage \& Family Review, 34, 285-310.

Friedlmeier, W., \& Trommsdorff, G. (1999). Emotion regulation in early childhood: A crosscultural comparison between German and Japanese toddlers. Journal of Cross-Cultural Psychology, 30, 684-711.

Gentzler, A. L., Contreras-Grau, J. M., Kerns, K. A., \& Weimer, B. L. (2005). Parent-child emotional communication and children's coping in middle childhood. Social Development, $14,591-612$.

Goldberg, S., Grusec, J. E., \& Jenkins, J. M. (1999). Confidence in protection: Arguments for a narrow definition of attachment. Journal of Family Psychology, 13, 475-483.

Goldsmith, H. H., Reilly, J., Lemery, K. S., Longley, S., \& Prescott, A. (1993). The laboratory temperament assessment battery (preschool version 0.5): Technical report. Madison, WI: Department of Psychology, University of Wisconsin.

Grusec, J. E. (2006). The development of moral behaviour and conscience from socialization perspective. In M. Killen, \& J. G. Smetana (Eds.), Handbook of moral development (pp. 243-265). Mahwah, NJ: Erlbaum.

Grusec, J. E., \& Davidov, M. (2007). Socialization in the family. In J. E. Grusec, \& P. D. Hastings (Eds.), Handbook of socialization: Theory and research (pp. 284-308). New York: Guilford.

Grusec, J. E., \& Goodnow, J. J. (1994). Impact of parental discipline methods on the child's internalization of values: A reconceptualization of current points of view. Developmental Psychology, 30, 4-19.

Grusec, J. E., Goodnow, J. J., \& Kuczynski, L. (2000). New directions in analyses of parenting contributions to children's acquisition of values. Child Development, 71, 205-211.

Harkness, S., Super, C. M., \& van Tijen, N. (2000). Individualism and the 'western mind' reconsidered: American and Dutch parent's ethnotheories of the child. In S. Harkness, C. Raeff, \& C. M. Super (Eds.), Variability in the social construction of the child (pp. 23-39). San Francisco, CA: Jossey-Bass.

Howse, R. B., Lange, G., Farran, D. C., \& Boyles, C. D. (2003). Motivation and self-regulation as predictors of achievement in economically disadvantaged young children. Journal of Experimental Education, 71, 151-174.

Jennings, K. D., Sandberg, I., Kelley, S. A., Valdes, L., Yaggi, K., Abrews, A., et al. (2008). Understanding of self and maternal warmth predict later self-regulation in toddlers. International Journal of Behavioral Development, 32, 108-118.

Jones, D. J., Forehand, R., Rakow, A., Colletti, C. J. M., McKee, L., \& Zalot, A. (2008). The specificity of maternal parenting behavior and child adjustment difficulties: A study of inner-city African American families. Journal of Family Psychology, 22, 181-192.

Karreman, A., van Tuijl, C., van Aken, M. A. G., \& Deković, M. (2006). Parenting and self-regulation in preschoolers: A meta-analysis. Infant and Child Development, 15, 561-579.

Keller, H., Lamm, B., Abels, M., Yovsi, R., Borke, J., Jensen, H., et al. (2006). Cultural models, socialization goals, and parenting ethnotheories: A multicultural analysis. Journal of CrossCultural Psychology, 37, 155-172.

Kochanska, G., \& Aksan, N. (2006). Children's conscience and self-regulation. Journal of Personality, 74, 1587-1617.

Kochanska, G., Aksan, N., Prisco, T. R., \& Adams, E. E. (2008). Mother-child and father-child mutually responsive orientation in the first 2 years and children's outcomes at preschool age: Mechanisms of influence. Child Development, 79, 30-44.

Kochanska, G., DeVet, K., Goldman, M., Murray, K. T., \& Putnam, S. P. (1994). Maternal reports of conscience development and temperament in young children. Child Development, $65,852-868$.

Kochanska, G., \& Murray, K. T. (2000). Mother-child mutually responsive orientation and conscience development: From toddler to early school age. Child Development, 71, 417-431. 
Kochanska, G., \& Thompson, R. A. (1997). The emergence and development of conscience in toddlerhood and early childhood. In J. E. Grusec, \& L. Kuczynski (Eds.), Parenting and children's internalization of values: A handbook of contemporary research (pp. 53-77). New York: Wiley.

Komsi, N., Räikkönen, K., Pesonen, A.-K., Heinonen, K., Keskivaara, P., Järvenpää, A.-L., et al. (2006). Continuity of temperament from infancy to middle childhood. Infant \& Behavior Development, 29, 494-508.

Kopp, C. B. (1982). Antecedents of self-regulation: A developmental perspective. Developmental Psychology, 18, 199-214.

Kopp, C. B., \& Wyer, N. (1994). Self-regulation in normal and atypical development. In D. Cichetti, \& S. L. Toth (Eds.), Disorders and dysfunction of the self (pp. 31-56). Rochester, NY: University of Rochester Press.

Landry, S. H., Smith, K. E., Swank, P. R., Assel, M. A., \& Vellet, S. (2001). Does early responsive parenting have a special importance for children's development or is consistency across early childhood necessary? Developmental Psychology, 37, 387-403.

Lengua, L. J. (2008). Anxiousness, frustration, and effortful control as moderators of the relation between parenting and adjustment in middle-childhood. Social Development, 17, $554-577$.

Maccoby, E. E. (2000). Parenting and its effects on children: On reading and misreading behavior genetics. Annual Review of Psychology, 51, 1-27.

Maccoby, E. E., \& Martin, J. A. (1983). Socialization in the context of the family: Parent-child interaction. In P. Mussen (Ed.), Handbook of child psychology (Vol. 4, pp. 1-101). New York: Wiley.

MacDonald, K. (1992). Warmth as a developmental construct: An evolutionary analysis. Child Development, 63, 753-773.

Matthews, J. S., Ponitz, C. C., \& Morrison, F. J. (2009). Early gender differences in selfregulation and academic achievement. Journal of Educational Psychology, 101, 689-704.

McClelland, G. H., \& Judd, C. M. (1993). Statistical difficulties of detecting interactions and moderator effects. Psychological Bulletin, 114, 376-390.

McClelland, M. M., Cameron, C. E., McDonald, C. C., Farris, C. L., Jewkes, A. M., \& Morrison, F. J. (2007). Links between behavioral regulation and preschoolers' literacy, vocabulary, and math skills. Developmental Psychology, 43, 947-959.

McClelland, M. M., Ponitz, C. C., Messersmith, E. E., \& Tominey, S. (2010). Self-regulation: The integration of cognition and emotion. In R. Lerner, \& W. Overton (Eds.), Handbook of life-span development (509-553). Hoboken, NJ: Wiley and Sons.

Mize, J., \& Pettit, G. S. (1997). Mothers' social coaching, mother-child relationship style, and children's peer competence: Is the medium the message? Child Development, 68, 312 332.

Organization for Economic Co-operation and Development (1999). Classifying educational programmes: Manual for ICSED-97 implementation in OECD countries. Retrieved December 4, 2007, from http://www.oecd.org/dataoecd/7/2/1962350.pdf

Paulussen-Hoogeboom, M. C., Stams, G. J. J. M., Hermanns, J. M. A., \& Peetsma, T. T. D. (2007). Child negative emotionality and parenting from infancy to preschool: A meta-analytic review. Developmental Psychology, 43, 438-453.

Pettit, G. S., Laird, R. D., Dodge, K. A., Bates, J. E., \& Criss, M. M. (2001). Antecedents and behavior-problem outcomes of parental monitoring and psychological control in early adolescence. Child Development, 72, 583-598.

Porter, C. L., Hart, C. H., Chongmin, Y., Robinson, C. C., Frost Olsen, S., Zeng, Q., et al. (2005). A comparative study of child temperament and parenting in Beijing, China and the western United States. International Journal of Behavioral Development, 29, 541-551.

Putnam, S. P., \& Rothbart, M. K. (2006). Development of short and very short forms from the children's behavior questionnaire. Journal of Personality Assessment, 87, 103-113.

Raffaelli, M., Crockett, L. J., \& Shen, Y.-L. (2005). Developmental stability and change in self-regulation from childhood to adolescence. The Journal of Genetic Psychology, 166, $54-75$.

Reitz, E., Deković, M., \& Meijer, A. M. (2006). Relations between parenting and externalizing and internalizing problem behaviour in early adolescence: Child behavior as moderator and predictor. Journal of Adolescence, 29, 419-436. 
Roberts, W. (1989). Criterion sortings for warmth and control for the Child Rearing Practices Q-Sort (1965). Retrieved October 25, 2006, from http://www.tru.ca/faculty/wlroberts/crpcriterions.pdf

Roberts, W. (1999). The socialization of emotion expression: Relations with prosocial behavior and competence in five samples. Canadian Journal of Behavioural Science, 31, 72-85.

Roberts, W., \& Strayer, J. (1987). Parents' responses to the emotional distress of their children: Relations with children's competence. Developmental Psychology, 23, 415-422.

Rothbart, M. K., Ahadi, S. A., Hershey, K. L., \& Fisher, P. (2001). Investigations of temperament at three to seven years: The children's behavior questionnaire. Child Development, 72 , 1394-1408.

Rothbart, M. K., \& Bates, J. E. (2006). Temperament. In N. Eisenberg, W. Damon, \& R. M. Lerner (Eds.), Handbook of child psychology: Vol. 3, social, emotional, and personality development (6th ed., pp. 99-166). Hoboken, NJ: Wiley.

Russell, A., \& Russell, G. (1996). Positive parenting and boys' and girls' misbehavior during a home observation. International Journal of Behavioral Development, 19, 291-307.

Stewart, S. M., \& Bond, M. H. (2002). A critical look at parenting research from the mainstream: Problems uncovered while adapting western research to non-western cultures. British Journal of Developmental Psychology, 20, 379-392.

Tildesley, E. A., \& Andrews, J. A. (2008). The development of children's intentions to use alcohol: Direct and indirect effects of parent alcohol use and parenting behaviors. Psychology of Addictive Behaviors, 22, 326-339.

Trommsdorff, G. (2006). Development of emotions as organized by culture. ISSBD Newsletter, $49,1-4$.

Trommsdorff, G. (2009a). Culture and development of self-regulation. Social and Personality Psychology Compass, 3, 1-15.

Trommsdorff, G. (2009b). Intergenerational relations and cultural transmission. In U. Schoenpflug (Ed.), Cultural transmission: Psychological, developmental, social, and methodological aspects (pp. 126-160). New York: Cambridge University Press.

Trommsdorff, G., \& Kornadt, H.-J. (2003). Parent-child relations in cross-cultural perspective. In L. Kuczynski (Ed.), Handbook of dynamics in parent-child relations (pp. 271-306). London: Sage.

Wong, M. M., Nigg, J. T., Zucker, R. A., Puttler, L. I., Fitzgerald, H. E., Jester, J. M., et al. (2006). Behavioral control and resiliency in the onset of alcohol and illicit drug use: A prospective study from preschool to adolescence. Child Development, 77, 1016-1033.

Xu, Y., Farver, J. A. M., \& Zhang, Z. (2009). Temperament, harsh and indulgent parenting, and Chinese children's proactive and reactive aggression. Child Development, 80, 244-258.

\section{Acknowledgments}

This research was financed by a grant from the German Research Foundation (DFG GZ, TR 169/14-2). This study is part of the project 'Developmental Conditions of Intentionality and Its Limits' (Principal Investigator: Prof. Dr. Gisela Trommsdorff) within the inter-disciplinary research group 'Limits of Intentionality' at the University of Konstanz, Germany. The authors wish to thank all the children and mothers who participated in or contributed to this project as well as the students of the University of Konstanz who assisted in the study. We thank Elizabeth Buckley-Reitz, Pennsylvania State University, PA; Maayan Davidov, University of Haifa, Israel; and Wolfgang Friedlmeier, Grand Valley State University, MI, for their valuable comments on earlier drafts. We also wish to thank the anonymous reviewers for their suggestions to improve the manuscript. 